\title{
Pleiotropic Effects of Proton Pump Inhibitors
}

\author{
Guest Editor: Yuji Naito
}

\section{Lansoprazole-Induced Improvement of Esophageal Submucosal Injury}

\author{
Shinichiro Mine ${ }^{1, *}$ and Yoshiya Tanaka ${ }^{2}$ \\ ${ }^{1}$ Department of Internal Medicine, Hagiwara Central Hospital, 1-10-1 Hagiwara Yahatanishi-ku, Kitakyushu 806-0059, \\ Japan \\ ${ }^{2}$ The First Department of Internal Medicine, University of Occupational and Environmental Health, Japan, School of \\ Medicine, Yahatanishi-ku, Kitakyushu 807-8555, Japan
}

Received 26 April, 2007; Accepted 1 May, 2007

\begin{abstract}
Summary The proton pump inhibitor, lansoprazole, is reported to have acid secretion inhibiting effect as well as anti-inflammatory effects such as inhibition of cytokine secretion from inflammatory cells. Clinically, excellent efficacy of lansoprazole is reported for not only gastric ulcer but also gastroesophageal reflux disease (GERD). Since GERD is categorized endoscopically into erosive esophagitis and non-erosive reflux disease, it is important to make accurate assessment of any improvement in the inflammatory process when using endoscopic ultrasonography (EUS) capable of visualizing the submucosal structure. We report here our experience in assessing the effect of treatment with lansoprazole on esophageal wall structure using EUS in patients with GERD. At baseline (before treatment), EUS showed abnormalities in the mucosa, submucosa and muscularis propria caused by inflammation, thickening of the entire esophageal wall and changes in the contractile properties of esophageal smooth muscles reflecting the effects of inflammation on the entire wall of the lower esophagus in reflux esophagitis regardless of whether it is erosive or endoscopically-negative. Treatment with lansoprazole resulted in normalization of esophageal wall structure and improvement of motility, suggesting that lansoprazole improves not only mucosal inflammation but also submucosal inflammation in GERD.
\end{abstract}

Key Words: lansoprazole, GERD, endoscopic ultrasonography, esophageal wall structure

\section{Lansoprazole and Gastroesophageal Reflux Disease}

Gastroesophageal reflux disease (GERD) is a chronic disorder that can potentially have a negative impact on quality of life (QOL) and increase the risk of esophageal damage [1-3]. While a large proportion of individuals report occasional or monthly heartburn, approximately $20 \%$ of the

\footnotetext{
*To whom correspondence should be addressed. Tel: +81 (93) 631-7511 Fax: +81 (93) 622-4181

E-mail: mine@hagiwara.or.jp
}

US adult population experience reflux symptoms on a weekly basis [4].

GERD is currently subclassified based on endoscopic findings into erosive esophagitis (EE) and non-erosive reflux disease (NERD) [5]. Although patients with EE have acid reflux, those with endoscopically-negative reflux disease represent a heterogeneous group for whom acid reflux is an explanation in some but not all. Previous studies indicated that about $50 \%$ of patients with endoscopically-negative disease have no evidence of pathological acid reflux as confirmed by $\mathrm{pH}$ monitoring and therefore, do not have NERD $[6,7]$. The Rome III Committee has suggested that 
such patients suffer from "functional heartburn" [8].

Proton pump inhibitor (PPI) therapy is effective for acidrelated symptoms. Lansoprazole, a substituted benzimidazole, selectively inhibits H, K-ATPase in the parietal cell membrane, and reduces gastric acid secretion [9]. Lansoprazole is more effective in the management of duodenal ulcer, gastric ulcer, and GERD and provides a faster relief of symptoms and healing than $\mathrm{H}_{2}$-receptor antagonists ( $\mathrm{H}_{2}-\mathrm{RAs}$ ) [10-12]. However, to our knowledge, the effects of lansoprazole on mucosal and entire wall injury of the lower esophagus have not evaluated.

\section{Histopathological Changes in Lower Esophagus in Patients with GERD}

Histopathological abnormalities have been described in both EE and NERD. Studies of esophageal mucosa exposed to luminal acidity by transmission electron microscopy (TEM) indicated that dilation of intercellular spaces is a useful marker of esophageal damage $[13,14]$. Recently, magnifying endoscopy has also shown that the presence of inflammatory cells, hyperplastic changes in the epithelium and dilated vessels in the papillae are recognized as histopathological markers of reflux disease, even in macroscopically-intact esophageal mucosa [15]. These changes precede the onset of macroscopic and histological lesions, and thus represent the earliest pathological alterations present in both EE and NERD. Furthermore, the presence of dilated intercellular spaces in acid-exposed rabbit esophagus has been related to episodes of high-acid content in the esophageal lumen, which damage intercellular junctions, reduce transepithelial resistance and increase paracellular permeability in the aciddamaged esophageal epithelium [16]. Thus, acidification of the intercellular space and of the cytosol seems to promote cell edema and necrosis.

\section{Endoscopic Ultrasonography Analysis of Esophageal Wall}

Endoscopy and examination of biopsy specimens are important for the diagnosis of EE and NERD, but their importance is limited to mucosal injury, such as erythema, edema of the mucosa, erosions and ulcers. Endoscopic

ultrasonography (EUS) is the only technique that allows detailed in vivo analysis of the esophageal wall and neighboring organs [17]. Therefore, EUS has been used for evaluation of the width, depth of ulcer craters, staging of cancers of the gastrointestinal (GI) tract, assessment of submucosal tumors and gut neuroendocrine tumors [18, 19].

On EUS, the esophageal wall is seen to consist of five layers of different echogenicities, roughly corresponding to the anatomic layers. We and others have reported that the thickness of the esophageal wall ranges between $2.43 \mathrm{~mm}$ and $0.16 \mathrm{~mm}$ at the gastroesophageal junction in normal subjects [20, 21]. In GERD, EUS can visualize changes in the layer structure with localized or diffuse thickening (Fig. 1) [21]. In our study, the total thicknesses of the lower esophageal wall, submucosal layer and muscularis propria layer measured by EUS in 20 normal adults (13 males and 7 females, age: $55 \pm 20$ years) were $2.44 \pm 0.4,1.03 \pm 0.2$, and $0.98 \pm 0.2 \mathrm{~mm}$ (mean $\pm \mathrm{SD}$ ), respectively. The respective mean total wall thickness and submucosal thickness were significantly greater in 25 patients with EE and NERD (14 males and 11 females, age: $65 \pm 13$ years, Table 1) [21]. A number of investigators have reported that such changes in the esophageal wall are associated with not only irreversible fibrosis [22], but also reversible edema and inflammatory cell infiltration [23].

(A)

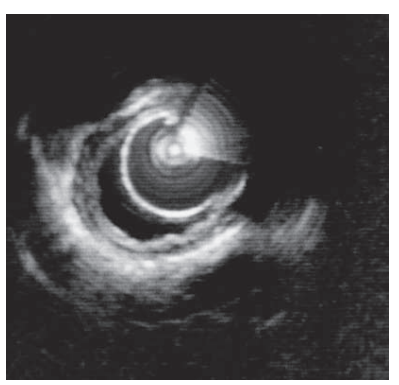

Fig. 1. Endoscopic ultrasonographic images of the esophageal wall. Comparison of submucosal and muscular layers between normal subjects (A) and patients with reflux esophagitis (B). Note the marked thickening of the submucosal and muscular layers in (B) with changes in echo density. Reprinted with permission [21].

Table 1. EUS evaluation of esophageal wall and Los Angeles classification

\begin{tabular}{lcccccc}
\hline & $\begin{array}{c}\text { control } \\
(n=20)\end{array}$ & $\begin{array}{c}\text { Grade O } \\
(n=4)\end{array}$ & $\begin{array}{c}\text { Grade A } \\
(n=12)\end{array}$ & $\begin{array}{c}\text { Grade B } \\
(n=5)\end{array}$ & $\begin{array}{c}\text { Grade C } \\
(n=2)\end{array}$ & $\begin{array}{c}\text { Grade D } \\
(n=2)\end{array}$ \\
\hline Total wall thickness $(\mathrm{mm})$ & $2.44 \pm 0.4$ & $3.67 \pm 1.5^{\mathrm{a}}$ & $3.65 \pm 0.8^{\mathrm{a}}$ & $4.38 \pm 1.4^{\mathrm{a}, \mathrm{b}}$ & $3.10 \pm 1.5$ & $4.0 \pm 1.4^{\mathrm{a}}$ \\
Submucosal layer $(\mathrm{mm})$ & $1.03 \pm 0.2$ & $1.36 \pm 0.9$ & $1.38 \pm 0.3^{\mathrm{c}}$ & $1.64 \pm 0.5^{\mathrm{c}}$ & $1.22 \pm 0.5$ & $1.46 \pm 0.3$ \\
Muscularis propria layer $(\mathrm{mm})$ & $0.98 \pm 0.2$ & $1.27 \pm 0.8$ & $1.24 \pm 0.3$ & $1.36 \pm 0.3$ & $1.11 \pm 0.4$ & $1.13 \pm 0.2$ \\
\hline
\end{tabular}

Data are mean $\pm \mathrm{SD}$ (mm, a: $p<0.001$, vs control, b: $p<0.05$, vs Grade A, c: $p<0.05$, vs control)

Reprinted with permission [21]. 


\section{Sustained Esophageal Contractions}

There is evidence to suggest that EUS-detectable increase in esophageal wall thickness and abnormalities of wall architecture correlate with inflammatory changes of esophageal wall as well as mechanical changes in GERD. Sustained esophageal contractions (SEC) are one of mechanisms proposed to explain the pathogenesis of heartburn in NERD. SEC, which represent prolonged contractions of the esophageal longitudinal smooth muscles, can be detected in vivo in humans as an increase in esophageal wall thickness by high-frequency EUS [24]. The concept that SEC are the cause of heartburn in NERD evolved from observations in a dozen of patients with GERD [25]. For instance, SEC were identified in all subjects during continuous intraluminal ultrasonography and correlated with the symptom of heartburn and acid reflux on $\mathrm{pH}$ monitoring (Bernstein test) [26]. In addition, another group reported that the positive correlation between SEC and heartburn in GERD is paralleled by an equally strong correlation between SEC and spontaneous chest pain in patients with atypical chest complaints [27].

Taken together, these data suggest that SEC correlate with chest pain of esophageal origin and impaired esophageal acid clearance and that it may be one expression of inflammatory damage of the muscle layer of the lower esophagus.

\section{Lansoprazole Results in Improvement of Esophageal Wall Thickness in Patients with GERD}

While most studies of GERD include patients with EE and NERD, support for the use of PPIs in patients with milder forms of the disease comes from recently conducted trials that documented the efficacy of PPIs as well as their superiority to $\mathrm{H}_{2}-\mathrm{RA}$ [28-30]. However, EUS evaluation of the healing process of GERD following treatment with PPI is intriguing. We compared the effects of lansoprazole and $\mathrm{H}_{2}$ RA in patients with GERD by using EUS before treatment and after completion of treatment.

In our study, two observations concerning EUS assessment deserve comment. First, lansoprazole administered at a dose of $30 \mathrm{mg} /$ day for 6 weeks resulted in rapid improvement of submucosal thickness of the lower esophagus as well as thickness of the entire wall of the lower esophagus. In contrast, treatment with famotidine, a $\mathrm{H}_{2}-\mathrm{RA}$, for 6 weeks failed to improve these abnormalities (Table 2) [21]. Second, the stratal structure of the esophageal wall and a good QOL were well maintained in the lansoprazole-treatment group, but reduction of the esophageal submucosal layer was observed with no change in the mucosal surface in the famotidine-treatment group (Fig. 2) [31].

The clinical improvement after PPI treatment in patients with EE can be related to the endoscopically-confirmed disappearance of EE; while in the case of NERD, where the esophageal mucosa appears normal at endoscopy and frequently also at histology, there was no improvement in any parameter that can explain the improvement of symptoms after treatment [32]. Recently, TEM demonstrated that PPI might induce ultrastructural healing of mucosal damage in both EE, NERD and asymptomatic subjects, based on complete resolution of widening of intercellular spaces [33]. Likewise, the acid control and anti-inflammatory actions of lansoprazole may have suppressive effects on the mucosal surface as well as inflammatory cell infiltration into the esophageal wall and may reverse alterations in the thickness of esophageal wall and abnormal architecture.

Furthermore, EUS analysis showed that treatment with lansoprazole improved esophageal wall structure, reduced esophageal wall thickness and persistent SEC [21, 31]. These changes suggest that the effects of lansoprazole are mediated through amelioration of esophageal motility and improvement of inflammation in GERD. Several investigators have reported that lansoprazole have potent inhibitory effects on spontaneous contractions and cause dose-dependent relaxation of smooth muscle in vitro [34, 35], probably through blockade of calcium channels. Therefore, lansoprazole

Table 2. Change in esophageal wall layers after PPI and $\mathrm{H}_{2}-\mathrm{RA}$ treatment

\begin{tabular}{lccc}
\hline Lansoprazole $(30 \mathrm{mg}) /$ famotidine $(40 \mathrm{mg})$ & pretreatment & after 6 weeks & after 12 weeks \\
\hline Total wall thickness & $4.28 \pm 0.98^{\mathrm{a}}$ & $2.70 \pm 0.34^{\mathrm{b}}$ & $3.34 \pm 0.94^{\mathrm{a}, \mathrm{c}}$ \\
Submucosal layer & $1.65 \pm 0.40^{\mathrm{a}}$ & $1.16 \pm 0.19^{\mathrm{b}}$ & $1.44 \pm 0.34$ \\
Muscularis propria layer & $1.46 \pm 0.41$ & $1.05 \pm 0.17$ & $1.20 \pm 0.24$ \\
\hline Famotidine (40 mg)/lansoprazole $(30 \mathrm{mg})$ & & & \\
\hline Total wall thickness & $4.06 \pm 0.74^{\mathrm{a}}$ & $4.48 \pm 1.11^{\mathrm{a}, \mathrm{b}}$ & $2.92 \pm 0.73^{\mathrm{c}}$ \\
Submucosal layer & $1.46 \pm 0.48$ & $1.75 \pm 0.48$ & $1.28 \pm 0.30^{\mathrm{c}}$ \\
Muscularis propria layer & $1.24 \pm 0.25$ & $1.55 \pm 0.47$ & $1.10 \pm 0.20$
\end{tabular}

Data are mean $\pm \mathrm{SD},(\mathrm{mm})$

a: $p<0.005$ vs control, b: $p<0.05$ vs pretreatment, c: $p<0.05$ vs after 6 weeks treatment

Reprinted with permission [21]. 
(A)

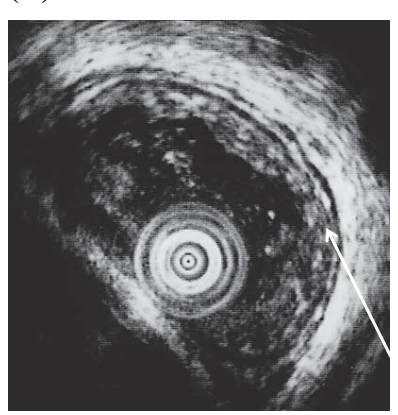

(B)

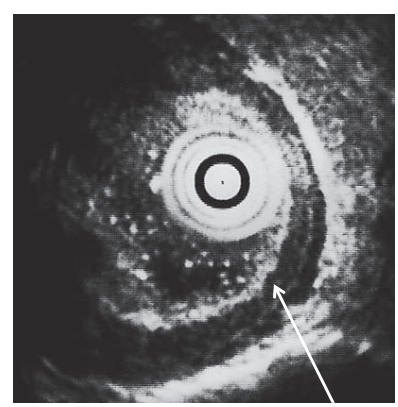

Fig. 2. Analysis of EUS findings after treatment of GERD patients. EUS analysis was performed after 16 weeks of treatment. The stratal structure of the esophageal wall was well maintained in most cases of the lansoprazolestepped-down group (A, white arrow). While reduction of the esophageal submucosal layer was observed, no change was noted in the mucosal surface in the famotidine stepped-down group (B, white arrow). Reprinted with permission [31].

may also improve esophageal dysmotility through inhibitory effects on contractions of esophageal smooth muscles.

In summary, using EUS, we reported the presence of esophageal wall thickening and abnormal architecture in ENRD as well as EE, and that lansoprazole was superior to $\mathrm{H}_{2}$-RAs in reversing the changes in esophageal wall thickness and abnormal architecture. This suggests that the lansoprazole treatment can improve esophageal submucosal injury as well as esophageal dysmotility.

\section{References}

[1] Vakil, N., van Zaten, S.V., Kahrilas, P., Dent, J., and Jones, R.: the Global Consensus Group: The montreal definition and classification of gastroesophageal reflux disease: a global evidence-based consensus. Am. J. Gastroenterol., 101, 1900-1920, 2006.

[2] Havelund, T., Lind, T., Wiklund, I., Glise, H., Hernqvist, H., Lauritsen, K., Lundell, L., Pedersen, S.A., Carlson, R., Junghard, O., Stubberod, A., and Anker-Hansen, O.: Quality of life in patients with heartburn but without esophagitis: effects of treatment with omeprazole. Am. J. Gastroenterol., 94, 1782-1789, 1999.

[3] Lagergren, J., Bergstrom, R., Lindgren, A., and Nyren, O.: Symptomatic gastroesophageal reflux as a risk factor for esophageal adenocarcinoma. N. Engl. J. Med., 340, 825-831, 1999.

[4] Locke, G.R., Tally, N.J., Fett, S.L., Zinsmeister, A.R., and Melton, L.J.: Prevalence and clinical spectrum of gastroesophageal reflux: a population-based study in Olmsted Country, Minnesota. Gastroenterology, 112, 1448-1456, 1997.

[5] Orland, R.C.: Reflux esophagitis, in Textbook of gastro- enterology, eds. By Yamada, T., Alpers, D.H., Owyang, C., Powell, D.W., and Laine, L., Lippincott Williams \& Wilkins, Philadelphia, pp. 1235-1263, 1999.

[6] Martinez, S.D., Malagon, I.B., Garewal, H.S., Cui, H., and Fass, R.: Non-erosive reflux disease (NERD) — acid reflux and symptom patterns. Aliment. Pharmacol. Ther, 17, 537545, 2003.

[7] Fass, R.: Epidemiology and pathophysiology of symptomatic gastroesophageal reflux disease. Am. J. Gastroenterol., 98 Suppl, S2-S7, 2003.

[8] Tack, J., Talley, N.J., Camilleri, M., Holtmann, G., Hu, P., Malagelada, J.-R., and Stanghellini, V.: Functional esophageal disorders. Gastroenterology, 130, 1459-1479, 2006.

[9] Spencer, C.M. and Faulds, D.: Lansoprazole: A reappraisal of its pharmacodynamic and pharmacokinetic properties, and its therapeutic efficacy in acid-related disorders. Drugs, 48, 404-430, 1994.

[10] Petite, J-P., Slama, J-L., Licht, H., Lemerez, M., Coste, T., Andrieu, J., Grimaud, J.C., Julien, H., Dupuis, J., and Sallerin, V.: Comparison of Lansoprazole (30 mg) and omeprazole $(20 \mathrm{mg})$ in the treatment of duodenal ulcers: A multicentric double-blind comparative trial. Gastroenterol. Clin. Biol., 17, 334-340, 1993.

[11] Florent, C., Forestier, S., and Joubert-Collin, M.: Lansoprazole versus omeprazole: Efficacy and safety in acute gastric ulcer. Gastroenterology, 104 Suppl, A80, 1993.

[12] Sontag, S.J., Kogut, D.G., Fleischmann, R., Campbell, D.R., Richter, J., Robinson, M., McFarland, M., Sabesin, S., Lehman, G.A., and Castell, D.: Lansoprazole heals erosive reflux esophagitis resistant to histamine $\mathrm{H}_{2}$-receptor antagonist therapy. Am. J. Gastroenterol., 92, 429-437, 1997.

[13] Calabrese, C., Fabbri, A., Bortolotti, M., Cenacchi, G., Areni, A., Scialpi, C., Miglioli, M., and Di Febo, G.: Dilated intercellular spaces as a marker of oesophageal damage: comparative results in gastro-oesophageal reflux disease with or without bile reflux. Aliment. Pharmacol. Ther, 18, 525532, 2003.

[14] Tobey, N.A., Carson, J.L., Alkiek, R.A., and Orlando, R.C.: Dilated intercellular spaces: A morphological feature of acid reflux-damaged human esophageal epithelium. Gastroenterology, 111, 1200-1205, 1996.

[15] Kiesslich, R., Kanzler, S., Vieth, M., Moehler, M., Neidig, J., Thanka Nadar, B.J., Schlling, D., Burg, J., Nafe, B., Neurath, M.F., and Galle, P.R.: Minimal change esophagitis: prospective comparison of endoscopic and histological makers between patients with non-erosive reflux disease and normal controls using magnifying endoscopy. Dig. Dis., 22, 221-227, 2004.

[16] Tobey, N.A., Hosseini, S.S., Argote, C.M., Dobrucali, A.M., Awayda, M.S., and Orlando, R.C.: Dilated intercellular spaces and shunt permeability in nonerosive acid-damaged esophageal epithelium. Am. J. Gastroenterol., 99, 13-22, 2004.

[17] Caletti, G.C., Bolondi, L., Zani, L., and Labo, G.: Technique of endoscopic ultrasonography investigation: esophagus, stomach and duodenum. Scand. J. Gastroenterol., 21 Suppl 123, 1-5, 1986.

[18] Tsukamoto, Y., Goto, H., Hase, S., Niwa, Y., Arisawa, T., 
Hayakawa, T., and Yoshikane, H.: Endosonographic evaluation of the quality of ulcer healing induced by proton pump inhibitors. J. Clin. Gastroenterol., 20 Suppl 2, S40-S43, 1995.

[19] Caletti, G.C., Fusaroli, P., and Bocus, P.: Endoscopic ultrasonography. Digestion, 59, 509-529, 1998.

[20] Caletti, G.C., Ferrari, A., Mattioli, S., Zannoli, R., Di Simone, M.P., Bocus, P., Gozzetti, G., and Barbara, L.: Endoscopy versus endoscopic ultrasonography in staging reflux esophagitis. Endoscopy, 26, 794-797, 1994.

[21] Mine, S., Fujisaki, T., Tabata, T., Matsuoka, H., Iida, T., Yamada, S., Tanaka, Y., Morimoto, I., Eto, S., and Aibe, T.: Ultrasonographic evaluation of lansoprazole-induced improvement of submucosal injury in patients with gastroesophageal reflux. Am. J. Gastroenterol., 95, 381-386, 2000.

[22] Sato, H., Murayama, I., Suda, K., Takeya, K., Tanaka, T., Takeuchi, M., and Kohashi, E.: Endoscopic ultrasonography for reflux esophagitis. Stomach and Intestine, 27, 10471051, 1992.

[23] Kawamura, O., Sekiguchi, T., Kusano, M., Horikoshi, T., Kikuchi, K., Miyazaki, M., Yamada, T., and Ohwada, T.: Endoscopic ultrasonographic abnormalities and lower esophageal sphincter function in reflux esophagitis. Dig. Dis. Sci., 40, 598-605, 1995.

[24] Pehlivanov, N., Liu, J., Kassab, G.S., Puckett, J.L., and Mittal, R.K.: Relationship between esophageal muscle thickness and intraluminal pressure: an ultrasonographic study. Am. J. Physiol. Gastrointest. Liver. Physiol., 280, G1093-G1098, 2001.

[25] Barlow, W.J. and Orlando, R.C.: The pathogenesis of heartburn in nonerosive reflux disease: a unifying hypothesis. Gastroenterology, 128, 771-778, 2005.

[26] Pehlivanov, N., Liu, J., and Mittal, R.K.: Sustained esophageal contraction: a motor correlate of heartburn symptom. Am. J. Physiol. Gastrointest. Liver. Physiol., 280, G743-G751, 2001.

[27] Balaban, D.H., Yamamoto, Y., Liu, J., Pehlivanov, N.,
Wisniewski, R., DeSilvey, D., and Mittal, R.K.: Sustained esophageal contraction: a marker of esophageal chest pain identified by intraluminal ultrasonography. Gastroenterology, 116, 29-37, 1999.

[28] Howden, C.W., Henning, J.M., Huang, B., Lukasik, N., and Freston, J.W.: Management of heartburn in a large, randomized, community-based study: comparison of four therapeutic strategies. Am. J. Gastroenterol., 96, 1704-1710, 2001.

[29] Richter, J.E., Kovacs, T.O.G., Greski-rose, P.A., Huang, B., and Fisher, R.: Lansoprazole in the treatment of heartburn in patients without erosive oesophagitis. Aliment. Pharmacol. Ther., 13, 795-804, 1999.

[30] Galmiche, J.P., Barthelemy, P., and Hamelin, B.: Treating the symptoms of gastro-oesophageal reflux disease: a doubleblind comparison of omeprazole and cisapride. Aliment. Pharmacol. Ther., 11, 765-773, 1997.

[31] Mine, S., Iida, T., Tabata, T., Kishikawa, H., and Tanaka, Y.: Management of symptoms in step-down therapy of gastroesophageal reflux disease. J. Gastroenterol. Hepatol., 20, 1365-1370, 2005.

[32] Schindlbeck, N.E., Weibecke, B., Klauser, A.G., Voderholzer, W.A., and Muller-Lissner, S.A.: Diagnostic value of histology in non-erosive gastroesophageal reflux disease. Gut, 39, 151-154, 1996.

[33] Calabrese, C., Bortolotti, M., Fabbri, A., Areni, A., Cenacchi, G., Scialpi, C., Miglioli, M., and Di Febo, G.: Reversibility of GERD ultrastructural alterations and relief of symptoms after omeprazole treatment. Am. J. Gastroenterol., 100, 537-542, 2005.

[34] Aydin, C., Sarac, B., Koyuncu, A., Yildirim, S., Sen, M., and Sarioglu, Y.: Relaxant effect of omeprazole and lansoprazole in guinea pig gallbladder muscle strips in vitro. J. Gastroenterol., 38, 765-771, 2003.

[35] Naseri, E. and Yenisehirli, A.: Proton pump inhibitors omeprazole and lansoprazole induce relaxation of isolated human arteries. Eur. J. Pharmacol., 531, 226-231, 2006. 